\title{
Papiloma escamoso do esófago: qual o papel etiológico do vírus do papiloma humano?
}

Cláudia Pinho, ${ }^{1}$ Rosa de Pinho ${ }^{2}$

\section{RESUMO}

Introdução: O papiloma escamoso do esófago (PEE) é uma lesão epitelial benigna, rara, geralmente assintomática e descoberta como um achado acidental durante a endoscopia digestiva alta (EDA). Dois fatores etiológicos possíveis têm sido descritos, sendo um deles a infeção pelo vírus do papiloma humano (HPV).

Descrição do caso: $O$ caso clínico apresentado relata o diagnóstico acidental de um PEE numa mulher de 38 anos, raça caucasiana, com antecedentes de doença dispéptica, que integra uma família reconstruída desde 2015. É fumadora e tem um estilo de vida sedentário, tendo diagnóstico de obesidade desde 2016. O seu Plano Nacional de Vacinação está atualizado, não tendo feito vacinação contra HPV. Esta utente vem a uma consulta programada de Saúde de Adultos, por apresentar um quadro de dor epigástrica ocasional, associada a pirose e enfartamento pós-prandial, com cerca de seis meses de evolução. Foram recomendadas alterações do estilo de vida, medidas higieno-dietéticas, prescrito omeprazol 20mg 1id. Passados três meses mantém queixas dispépticas apesar de cumprida prova terapêutica e foi pedida EDA que revelou um "pólipo com $4 \mathrm{~mm}$ (a $30 \mathrm{~cm}$ dos incisivos) sugestivo de papiloma, removido na totalidade com pinça a frio". O estudo histológico revelou "fragmentos da mucosa esofágica compatíveis com papiloma escamoso".

Comentário: O caso clínico apresentado relata o diagnóstico e o seguimento de um PEE numa mulher com fatores de risco para provável etiologia por infeção por vírus do papiloma humano (HPV). Para a abordagem deste tipo de lesão, com possível etiologia vírica, não existem recomendações oficiais dos prazos de vigilância ou da atitude preventiva necessária ao nível dos cuidados de saúde primários, pelo que foi procurada a colaboração da especialidade de gastrenterologia. Este caso procura relembrar os fatores etiológicos que podem estar na base deste tipo de lesões e o papel do médico de família no diagnóstico, seguimento e vigilância dos fatores de risco que podem favorecer o aparecimento deste tipo de lesões.

Palavras-chave: Papiloma; Papillomaviridae; Mucosa esofágica; Medicina geral e familiar.

\section{INTRODUÇÃO}

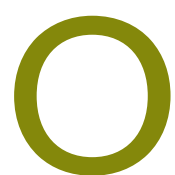

papiloma escamoso do esófago (PEE) é uma lesão epitelial benigna, rara, geralmente assintomática e descoberta como um achado acidental durante a endoscopia digestiva alta (EDA). Foi descrito pela primeira vez por Adler e colaboradores, $1959 .{ }^{1}$ A prevalência do PEE va-

1. Médico Interno de Medicina Geral e Familiar. USF Vale do Vouga - São João da Madeira.

2. Médico Assistente de Medicina Geral e Familiar. USF Vale do Vouga - São João da Madeira. ria de 0,01 a $0,45 \%$ de acordo com as séries endoscópicas, sendo mais frequente em homens de meia-idade. O PEE está geralmente localizado no esófago distal e assemelha-se a uma única lesão séssil pequena, esbranquiçada e elevada. $\mathrm{O}$ aspeto endoscópico é característico, mas não patognomónico. ${ }^{2}$ Para além da irritação crónica da mucosa, a infeção pelo vírus do papiloma humano (HPV) tem sido descrita como um dos fatores etiológicos envolvidos no desenvolvimento deste tipo de lesões. Embora o seu papel na etiopatogenia e potencial de malignidade ainda permaneça por esclarecer, alguns estudos reconhecem a importância da 
pesquisa destes vírus nestes casos, uma vez que a presença de vírus com potencial de causar lesões pré-malignas ou malignas poderia modificar o seguimento destes doentes. ${ }^{4}$

Este caso procura relembrar os fatores etiológicos que podem estar na base do PEE e o papel do médico de família no diagnóstico, seguimento e vigilância dos fatores de risco que podem favorecer o aparecimento deste tipo de lesões.

\section{DESCRIÇÃO DO CASO}

\section{Identificação e história pessoal}

Mulher de 38 anos, raça caucasiana, natural de Macieira de Sarnes, residente em São João da Madeira. Tem uma escolaridade de quatro anos e trabalha como operadora de máquinas no fabrico de calçado.

Trata-se de uma utente com antecedentes de perturbação ansiosa/depressiva, desde 2007, com história de um episódio de automutilação em 2013, sendo seguida em consulta de psiquiatria desde então. Em 2008 apresentou queixas de dispepsia, pelas quais fez uma EDA, que revelou sinais sugestivos de gastrite, tendo sido medicada com inibidor da bomba de protões, com resolução dos sintomas. Foi submetida a colecistectomia em janeiro de 2009, por um quadro de litíase vesicular. Tem diagnóstico de hipertensão arterial (HTA) essencial desde 2017. É fumadora desde 2011 (com uma carga tabágica de 10 unidades maço-ano), sem consumos etílicos ou outros consumos toxicológicos conhecidos. Tem um estilo de vida sedentário, tendo diagnóstico de obesidade desde 2016. O seu Plano Nacional de Vacinação está atualizado, não tendo feito vacinação contra HPV. A última citologia cervico-vaginal (CCV) da utente foi em 2016, pelo programa de rastreio do cancro do colo do útero e encontrava-se sem alterações. Desconhece alergias medicamentosas ou alimentares. A sua medicação atual inclui sertralina 50mg id e ramipril 2,5mg id.

\section{Caracterização familiar}

A utente integra uma família reconstruída, vivendo uma relação homossexual com a atual parceira desde 2015. A utente classifica a sua família como altamente funcional (9 pontos), segundo o Apgar Familiar de Smilkstein e integra uma classe socioeconómica IV (média-baixa), segundo a escala de Graffar. O genograma desta família e a psicofigura de Mitchell encontram-se representados na Figura 1.

\section{História da doença atual}

Consulta programada de saúde de adultos (20/02/2018)

A utente marca esta consulta por apresentar um quadro de dor epigástrica ocasional, associada a pirose e enfartamento pós-prandial, com cerca de seis meses de evolução. Negava regurgitação, disfagia, odinofagia, vómitos, alterações do trânsito intestinal ou perda de peso. O exame objetivo não tinha alterações de relevo.

Face às queixas apresentadas colocaram-se, como hipóteses de diagnóstico, uma doença do esófago (motilidade $v s$ DRGE) ou uma alteração funcional do estômago, com provável agudização de um quadro de gastrite diagnosticado em 2008. Tendo em conta o longo período assintomático, foram inicialmente recomendadas alterações do estilo de vida e medidas higienodietéticas, prescrito omeprazol 20mg 1id, como prova terapêutica, e marcada consulta de reavaliação. A utente volta três meses depois, mantendo as queixas dispépticas, apesar de cumprida a prova terapêutica, e foi pedida a EDA.

\section{Consulta programada de saúde de adultos (10/07/2018)}

A utente volta à consulta com o resultado da EDA, que revelou um "pólipo com 4mm (a 30cm dos incisivos) sugestivo de papiloma, removido na totalidade com pinça a frio. Hérnia de hiato com transição esofagogástrica aos 35cm e impressão diafragmática aos 38cm". O estudo histológico revelou "fragmentos da mucosa esofágica compatíveis com papiloma escamoso. Lesões de gastrite crónica em fragmentos da mucosa gástrica do corpo e antro, com sinais de ligeira atividade e com evidência de atrofia ligeira, mas sem sinais de metaplasia intestinal ou displasia. Helicobacter pylori positivo."

Perante os resultados da EDA, a utente foi medicada para a infeção por Helicobacter pylori com terapia tripla (omeprazol 20mg + amoxicilina 1000mg + levofloxacina 500mg) e reforçadas a medidas higieno-dietéticas. Tendo em conta os hábitos tabágicos da utente e o insucesso das tentativas anteriores de deixar de fumar, foi acordado com a utente a referenciação para consulta de cessação tabágica.

Para esclarecimento do seguimento mais adequado ao diagnóstico de papiloma escamoso do esófago foi 


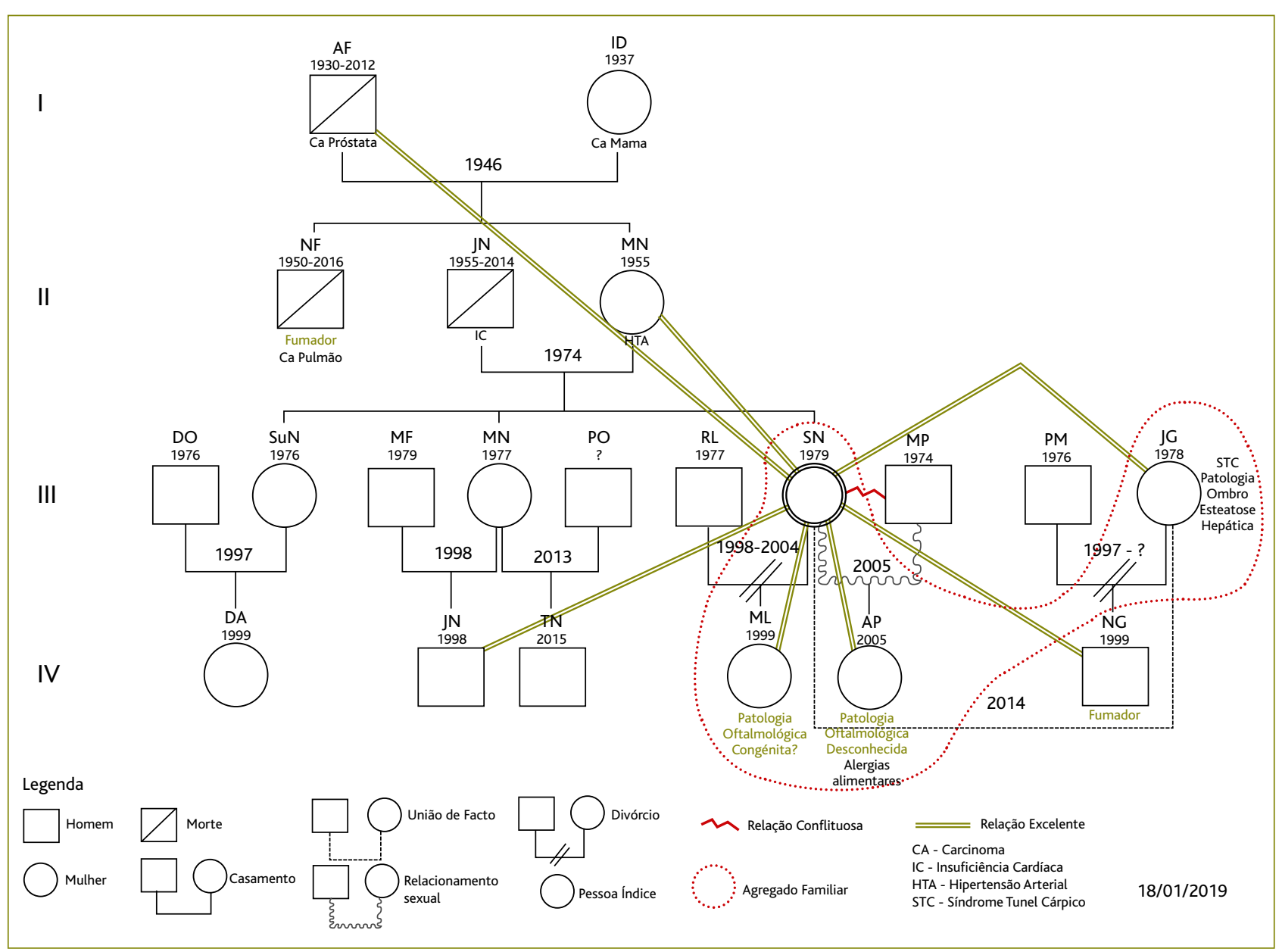

Figura 1. Genograma familiar (janeiro 2019).

contactado o serviço de gastrenterologia do centro hospitalar de referência, que recomendou uma reavaliação da utente, por EDA, ao fim de seis meses, tendo em conta que o papiloma foi removido na sua totalidade, para avaliar a recorrência do mesmo ou o aparecimento de novas lesões.

\section{Consulta programada de saúde de adultos (15/01/2019)}

Nesta consulta, a utente, manifestando ligeira melhoria das queixas dispépticas, volta com o resultado da nova EDA, que revelou "pólipo com $4 \mathrm{~mm}$ (a $35 \mathrm{~cm}$ dos incisivos) sugestivo de papiloma, removido na totalidade com pinça a frio." O estudo histológico revelou " $p a-$ piloma escamoso, com aspetos sugestivos de infeção vírica."

Nesta EDA, a utente mantinha as lesões de gastrite crónica superficial, já sem sinais de atividade e sem sinais de atrofia, e mantinha a hérnia de hiato, descrita na EDA anterior.

Tendo em conta o aparecimento de uma nova lesão e a possibilidade de infeção vírica, a utente foi referenciada para consulta hospitalar de gastrentetologia.

\section{COMENTÁRIO}

O caso clínico apresentado é um exemplo típico de como um achado acidental da EDA se pode converter num diagnóstico de PEE.

Ainda que se trate de uma lesão histologicamente benigna e geralmente assintomática, alguns casos de disfagia foram associados ao crescimento do papiloma, com melhora após a resseção endoscópica e também de estenose acentuada do lúmen do esófago com 
necessidade de dilatações frequentes, pelo que a sua resseção é recomendada. Os tratamentos do PEE atualmente descritos incluem a criocirurgia, o laser e a excisão eletrocirúrgica com pinças de biópsia. ${ }^{6-7}$

A patogénese do PEE permanece desconhecida; contudo, dois fatores etiológicos têm sido propostos. O primeiro é a irritação crónica da mucosa devido a fatores químicos e/ou mecânicos, como a doença do refluxo, trauma e o consumo de álcool ou tabagismo. Isto pode explicar por que dois terços dos casos de PEE se localizam no terço inferior do esófago, um local exposto a irritação crónica do refluxo de ácido gástrico.

O segundo fator etiológico proposto foi a infeção pelo vírus do papiloma humano (HPV) que, embora tenha sido identificado em algumas lesões, o seu papel na etiopatogenia do PEE permanece por esclarecer, assim como o seu potencial de malignidade. ${ }^{3}$ Ainda assim, alguns estudos reconhecem a importância da pesquisa deste vírus nestes casos, uma vez que a presença de vírus com maior potencial de causar lesões pré-malignas ou malignas poderia modificar o seguimento destes doentes. ${ }^{4}$

Neste caso clínico, a utente apresentava alguns fatores etiológicos possíveis ao nível da irritação crónica da mucosa, como o tabagismo, a obesidade, a gastrite e a hérnia de hiato. Por isso, foram recomendadas alterações de estilo de vida (com ênfase nas medidas antirrefluxo) e correção dos erros alimentares da utente ao longo das consultas. Foi ainda elaborado um plano alimentar com o objetivo de redução do peso e dos sintomas dispépticos e foi acordada com a utente a referenciação para consulta de cessação tabágica, uma vez que a utente se encontrava motivada a deixar de fumar e as anteriores tentativas não tiveram sucesso.

Ao nível da possível infeção pelo HPV, a utente tem como fatores de risco os múltiplos relacionamentos heterossexuais, com vários contactos sexuais desprotegidos, anteriores ao atual relacionamento homossexual, juntamente com o facto de nunca ter sido vacinada contra a infeção por HPV.

No tubo digestivo, o HPV pode ser encontrado ao nível da boca, faringe, esófago e ânus, infetando exclusivamente células epiteliais. A sua via de transmissão é por contacto direto e, embora a infeção oral se associe a práticas sexuais de risco, nenhuma relação foi, até agora, estabelecida entre este tipo de práticas e o de- senvolvimento de papilomas esofágicos. ${ }^{5}$ Apesar disso, e pensando no facto dos PEE desta utente terem uma localização mais proximal (o primeiro a $30 \mathrm{~cm}$ e o segundo a $35 \mathrm{~cm}$ dos incisivos), ao contrário da maioria dos casos, e da presença de aspetos sugestivos de infeção vírica descritos pela última EDA, a probabilidade de uma etiologia viral ficou reforçada. Uma vez que a CCV da utente foi atualizada em 2016 pelo programa de rastreio do cancro do colo do útero, encontrando-se sem alterações, a vigilância da utente foi mantida dentro do esquema recomendado pela DGS. Quanto à parceira, a última CCV, realizada em 2016, não foi incluída no programa de rastreio, pelo que foi aconselhada a sua atualização. Neste sentido, a utente e a companheira foram também sensibilizadas para o modo de propagação do vírus e foi recomendada a utilização de contraceção de barreira até que fossem obtidos mais esclarecimentos acerca da etiologia dos PEE da utente. A vacinação contra o HPV foi proposta à utente e à sua atual companheira, uma vez que corresponde a uma medida preventiva na infeção por variadas estirpes do vírus; contudo, a condição socioeconómica da utente foi um fator limitante na aplicação desta medida.

Uma vez que não foram encontradas recomendações oficiais dos prazos de vigilância adequados a este tipo de papilomas foram seguidas as recomendações da colega de gastrenterologia, tendo-se marcado reavaliação e repetição da EDA no prazo de seis meses. Embora a resseção seja completa, o PEE pode recidivar com frequência, ${ }^{8}$ o que se verificou neste caso, com o aparecimento de uma nova lesão, seis meses depois, com as mesmas dimensões, localizada a cinco centímetros da lesão anterior. A presença de um novo papiloma com aspetos sugestivos de infeção vírica, aliada à presença de fatores de risco para infeção por HPV, levou à necessidade de encaminhar a utente para consulta hospitalar de gastrenterologia para um seguimento mais adequado e melhor caracterização da etiologia das lesões, nomeadamente por tipagem do genótipo viral presente na última lesão. $\mathrm{O}$ tratamento do PEE tem, em primeiro lugar, o benefício de evitar as complicações associadas ao seu crescimento. Em segundo lugar, caso seja confirmada a etiologia vírica, o tratamento tem o benefício de tentar o controlo da infeção que, embora não tenha atualmente um papel claro no potencial de malignidade deste tipo de lesões, pode ser um 
potencial vetor de transmissão deste vírus a outros indivíduos, podendo permitir a sua proliferação ao nível da mucosa vaginal ou da laringe, locais onde o potencial de malignidade deste vírus é já bem conhecido. Neste caso, o papel do médico de família passa essencialmente por reconhecer os fatores etiológicos que poderão estar na base deste tipo de lesão, atuando ao nível da prevenção e do controlo dos fatores de risco apresentados pelo utente e referenciando para a especialidade hospitalar de gastrenterologia os casos que apresentem necessidade de uma investigação etiológica e de um tratamento mais especializados, nomeadamente os casos com potencial etiologia vírica.

\section{REFERÊNCIAS BIBLIOGRÁFICAS}

1. Adler RH, Carberry DM, Ross CA. Papilloma of the esophagus: association with hiatal hernia. J Thorac Surg. 1959;37(5):625-35.

2. Ponce-Rodríguez FM, Ponce-Santoyo M, Román-Castellani EV. Papilomatosis esofágica: a propósito de un caso [Esofagic papilomatosis: in relation to a case]. Rev Med Electron. 2011;33(5):620-5. Spanish

3. Xu W, Liu Z, Bao Q, Qian Z. Viruses, other pathogenic microorganisms and esophageal cancer. Gastrointest Tumors. 2015;2(1):2-13.

4. d'Huart MC, Chevaux JB, Bressenot AM, Froment N, Vuitton L, Degano SV, et al. Prevalence of esophageal squamous papilloma (ESP) and as- sociated cancer in northeastern France. Endosc Int Open. 2015;3(2):E101-6.

5. Zur Hausen H. Papillomaviruses and cancer: from basic studies to clinical application. Nat Rev Cancer. 2002;2(5):342-50.

6. Narayani RI, Young GS. Recurrent proximal esophageal stricture associated with dysplasia in squamous cell papillomatosis. Gastrointest Endosc. 2002;56(4):591-4.

7. Sandvik AK, Aase S, Kveberg KH, Dalen A, Folvik M, Naess O. Papillomatosis of the esophagus. J Clin Gastroenterol. 1996;22(1):35-7.

8. Pineda-Oliva OJ, Valencia-Romero A, Valdivia-Balbuena M, Díaz-Oyola M, Cuevas-Osorio V, Soto-Pérez JC, et al. Papiloma escamoso del esófago: reporte de 31 casos em um hospital de tercer nível [Esophageal squamous papilloma: report of 31 cases in a tertiary hospital]. Endoscopia. 2015;27(1):31-5. Spanish

\section{CONFLITO DE INTERESSES}

Os autores declaram não ter quaisquer conflitos de interesse.

\section{ENDEREÇO PARA CORRESPONDÊNCIA}

Cláudia Pinho

E-mail: claudiadeoliveira@gmail.com

https://orcid.org/0000-0002-8040-2565

Recebido em 22-11-2018

Aceite para publicação em 30-03-2019

\section{ABSTRACT}

\section{ESOPHAGEAL SQUAMOUS CELL CARCINOMA: IS THE HUMAN PAPILLOMAVIRUS A RISK FACTOR?}

Introduction: Esophagus squamous papilloma (PEE) is a rare, benign epithelial lesion, usually asymptomatic and discovered as an accidental finding during upper digestive endoscopy (EDA). Two possible etiological factors have been described, one of them is Human Papillomavirus (HPV) infection.

Case report: The presented clinical case reports the accidental diagnosis of a PEE in a caucasian woman with a history of the dyspeptic disease, who is a member of a reconstructed family since 2015. She is a smoker and has a sedentary lifestyle, having been diagnosed with obesity since 2016. Her National Vaccination Plan is up to date, but she never had been vaccinated against HPV. This patient comes to a scheduled consultation, presenting an occasional epigastric pain associated with heartburn and postprandial infarction, with 6 months of evolution. Dietary measures were recommended, and a proton pump inhibitor was prescribed. After three months she maintained dyspeptic complaints despite the therapeutic test and endoscopy was requested which revealed a "polyp with $4 \mathrm{~mm}$ (at $30 \mathrm{~cm}$ of the incisors) suggestive of papilloma, completely removed with cold tweezers". The histological study revealed "fragments of the esophageal mucosa compatible with squamous papilloma".

Comments: In order to approach this type of lesion, with possible viral etiology, there are no official recommendations of surveillance or the preventive attitude required in the primary health care level, so the collaboration of the gastroenterology was essential. This case seeks to recall the etiological factors that may be the basis of this type of lesions and the role of the family physician in the diagnosis, follow-up, and surveillance of risk factors that may favor the appearance of this type of lesions.

Keywords: Papilloma; Papillomaviridae; Esophageal mucosa; Family practice. 